\title{
Reading Dynamics of Exophoric Persons: A Study with Infrared Reflexion Oculography (IROG)
}

\section{Elfriede Stangler-Zuschrott ${ }^{1 *}$ and Alex Salomon ${ }^{2}$}

${ }^{1}$ University Clinic for Ophthalmology and Optometry Emer, Vienna, Austria

${ }^{2}$ Department for Ophthalmology and Optometry at Clinic Donaustadt, Vienna,

Austria

*Corresponding Author: Elfriede Stangler-Zuschrott, Professor, University Clinic for Ophthalmology and Optometry Emer, Vienna, Austria.
Received: April 22, 2021

Published: May 14, 2021

(C) All rights are reserved by Elfriede

Stangler-Zuschrott and Alex Salomon.

\section{Abstract}

The reading traces of 32 patients aged on average 32 years were registered by a binocular simultaneous infrared reflexion oculography unit (IROG). Seven of them had exophoria but no complaints, while 13 exophorics suffered from asthenopia or the inability to work at the VDU. The patients were compared to 12 persons with normal binocular vision. The differences in reading speed between paper-printed texts and screen reading was statistically highly significant. Normal persons showed a retardation of $11 \%$. Exophoric persons without complaints showed a delay of $23 \%$; although they were the best readers, they lost too much time in overcorrecting their divergence, the result could even be a convergent position. Exophoric persons with complaints showed a retardation of only $9 \%$ when reading on the screen because they had remarkable difficulties even in reading paper-printed texts: moments of decompensation into squint, unilateral suppression, readings stops, and fatigue. In general, the screen intensifies preexisting defects. The orthoptic findings correlated with the degree of eye strain. The worst cases had the largest squint angle, the lowest fusion range, and the weakest convergence power.

Keywords: Exophoria and Reading at the VDU; Binocularity and Reading Speed; The Quality of Paper-prints and Reading Speed; Micro Motility and Eye Strain; Infrared-reflection-oculography (IROG)

\section{Abbreviations}

VA: Visual Acuity; RE: Right Eye; LE: Left Eye

\section{Introduction}

Exophoria, the latent divergent squint, is very common in humans and is supposed to cause problems in working at a visual display unit (VDU). The aim of the study was to identify factors in the binocular behavior of exophorics, which may produce subjective eye strain. In addition to the static binocular state, we explored the dynamic process of reading texts in various forms for a prolonged period of time. The results were compared to those of normal or- thophoric test persons. Eye movements during reading should be recorded objectively and evaluated in regard of their accuracy, velocity and binocular connection.

\section{Methods}

Technical equipment

- A standard Computer with a VGA graphic card and a monitor $(640 \times 480 / 0 \mathrm{~Hz})$.

- The high-resolution four-channel infrared reflexion oculography unit (IROG) after Bouis (Figure 1) [1] was combined with a four-channel high-speed recorder. The IROG device allows exact centralization of the bilateral eye position and 
simultaneous binocular registration of their movements.

- The test person had his/her head fixed and was asked to move only the eyes and not the body while reading. Any refractive error was corrected with steady glasses. The patient looked straight into free space. Horizontal eye excursions to $15^{\circ}$ and vertical excursions to $10^{\circ}$ could be registered.

- A music-stand for texts at a distance of $50 \mathrm{~cm}$.

- The usual equipment of an orthoptic department to examine the binocular state of a test person.

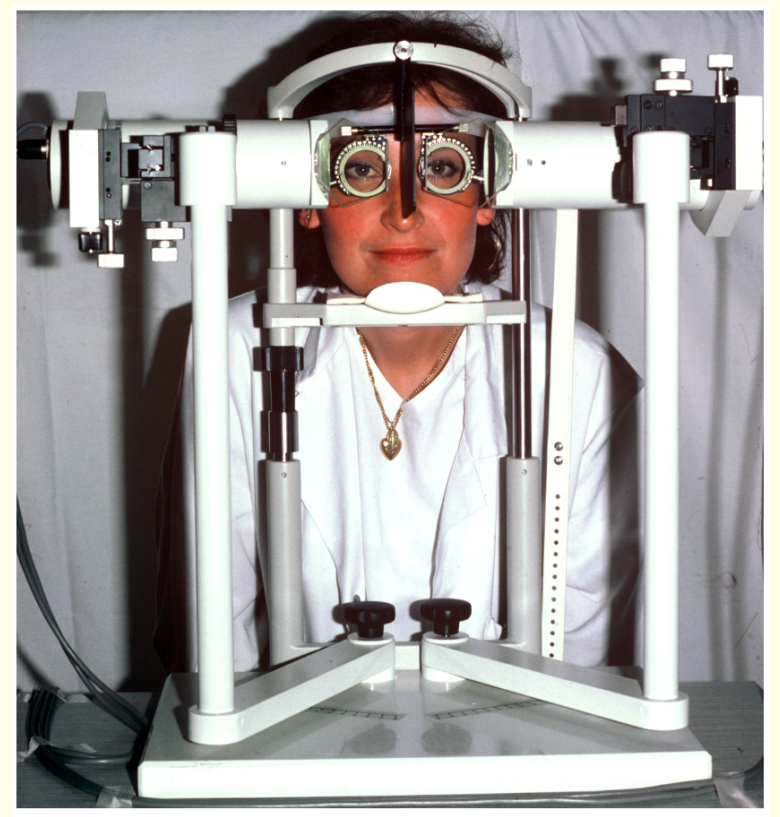

Figure 1: The four-channel infrared-oculographic unit (IROG).

\section{Performing the tests}

The distance between the eyes and the text was $50 \mathrm{~cm}$ for printed texts as well as the computer screen; the room illumination was identical. The test person was asked to read four paragraphs (19 lines each) silently at the VDU, on paper, printed with a pin-writer (low quality of print), on paper, printed with a laser printer.

All prints had letters of identical size, type and numbers; short words were given preference. The contents of the paragraphs were similar and easy to understand (legends). The test persons could take a break of five minutes after reading the four paragraphs on each type of display.

\section{Material}

We examined 32 outpatients, aged 17 - 52 years (mean age 31 years) with a VA of 1,0 in both eyes and an intact visual field. No one of our test persons had symptoms of "dry eyes" which could cause frequent blinking. In addition to the orthoptic check-up, we performed an IROG study. Patients were divided into three groups: orthophoric persons $(n=12)$, exophoric persons without complaints $(n=7)$. and exophoric patients with complaints $(n=13)$ such as headache or difficulties or inability to work at the VDU.

\section{Results and Discussion}

\section{Selected patients and typical reading traces}

Case 1

Female, 28 years, normal binocular findings. This patient served as an example of normal tracings.

Figure 2 the horizontal movements (upper traces LX and RX) from left to right proceeded in small steps and so-called reading positions. A horizontal saccadic eye movement occurred at the end of a line to fix the next line. Horizontal eye positions and movements were nearly identical for both eyes. The starting position for each line was always the same. Vertical movements (lower traces LY, RY) slid downward slowly.
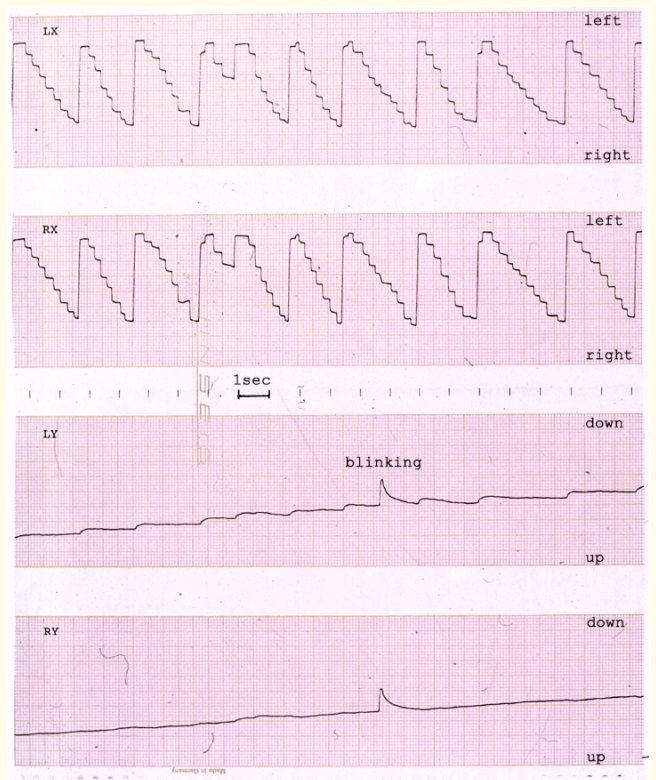

Figure 2: Binocular reading traces of a normal test person, age 28 years. 
The function of reading is managed by the saccadic system of brain and proceeds in small saccades, which must be stopped in order to obtain the intermediate reading positions [2]. Thus, the quick series of innervations and inhibitions must be learned and trained in childhood.

\section{Case 2}

Male, 42 years, VA RA = LA 1,0, exophoria, squint angle for distance $-2 \Delta$, for near fixation $-10 \Delta$, near point of convergence $20 \mathrm{~cm}$, fusion range $8 \Delta$. Working at the VDU was strenuous and the patient felt the right eye drifting away.

Figure 3 patient 2 read a laser-printed text. The more exact movements of the left eye were indicative of the dominance of this eye. The difficulties started at lines 27 - 31. The reading movements stopped for about 2 seconds because the right eye drifted about $3^{\circ}$ into divergence, followed by corrective fusional movements of both eyes. After these moments which lacked sensory perception -such as suppression -the patient continued reading. One line later the same event followed and the dominant left eye made a right-sided movement of about $5^{\circ}$ to pick up binocularity with the fellow eye. The tests series read on the screen were associated with the same symptoms, but started earlier (after a few test lines).
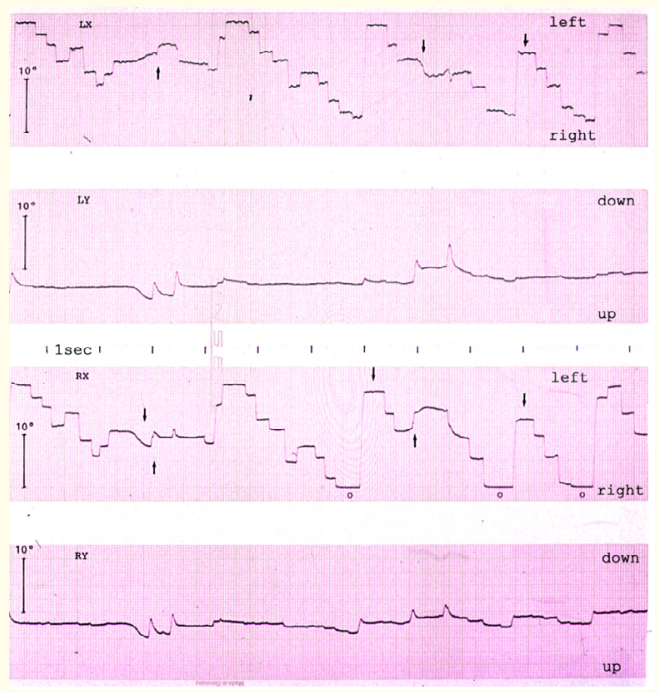

Figure 3: Patient 2, binocular simultaneous reading of laser-printed text, line 27-31.
Figure 4 the same patient was asked to repeat the test after working for four hours at VDU. After a few minutes of reading on the screen, he was unable to continue and was blinking persistently.
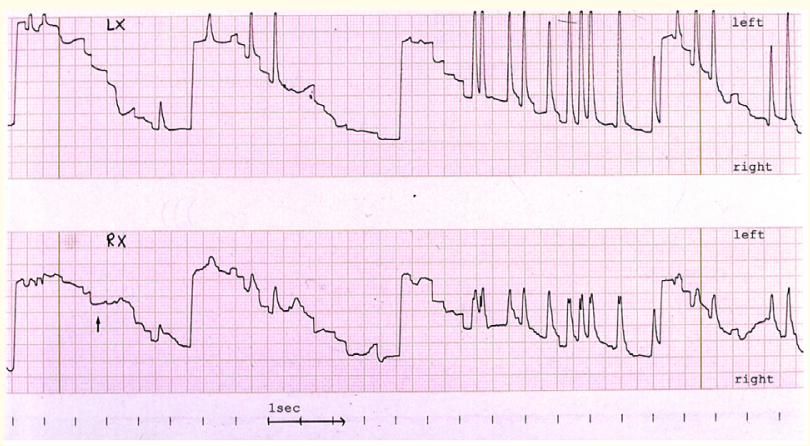

Figure 4: Patient 2. at the end of the computer test the patient is exhausted.

After a short break the same patient read the texts of a pinwriter and of a laser-printer almost normally and very rapidly. The different print quality of the texts did not appear to make any problem. Yet, the tracings showed that the right eye tended to drift into divergence.

The tests clearly showed that this patient was not qualified to work at a VDU, but was able to work with documents printed on paper.

Case 3

Female, 37 years, exophoria, squint angle for distance $=$ near $-9 \Delta$, convergence to $20 \mathrm{~cm}$, fusion range $12 \Delta$, asthenopia.

Figure 5 the reading traces of case 3 revealed a dominance of the right eye. The RE movements were fairly exact; the LE slid along indifferently. The very small but numerous reading positions were remarkable and a sign of a habitual very slow reading. The patient experienced additional difficulties when reading the second paragraph of the text on the monitor: many stops of about 1 second each and repeated blinking.

\section{Case 4}

Female, 25 years, exophoria, squint angle for distance - $8 \Delta$, near $-16 \Delta$, fusion range $20 \Delta$. The patient wore $4 \Delta$ base-in prism glasses and had difficulties when working at the VDU. 

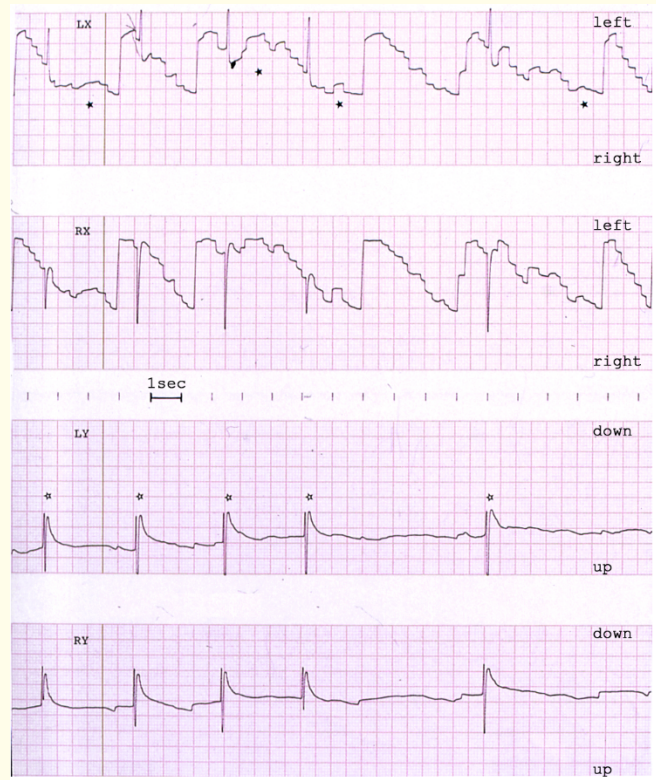

Figure 5: Patient 3 reading computer- text. Black stars sign stops of reading, white stars mean frequent blinking as an asthenopic sign.

Figure 6 case 4 was an example of overcompensating the latent divergence. The horizontal dominant RE remained constantly in the same reading position, meanwhile the LE drifted slowly into convergence. This convergent deviation was less (to $+4^{\circ}$ ) when reading laser-printed texts, but increased to $+10^{\circ}$ when reading at the screen (Table 1). The binocular horizontal traces of reading at the VDU (A) were marked by a speed retardation of $17.6 \%$ compared to reading laser-printed text $(B)$.

\section{Case 5}

Female, 30 years, exophoria, squint angle for distance $0^{\circ}$, near $-10 \Delta$, convergence to $40 \mathrm{~cm}$, fusion range $10 \Delta$, no asthenopic complaints.

Figure 7 the dominant RE moved exactly, the LE was not quite accurate in fixing the next line. Suddenly, within 1 second, the LE overcompensated to the right side into a convergent position. In the following second, both eyes moved synchronously a few degrees to the left, and thus the RE gave an impulse for the LE to regain its correct position.

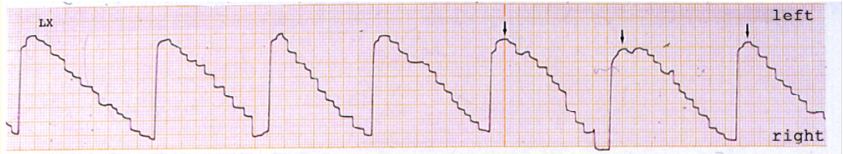

A

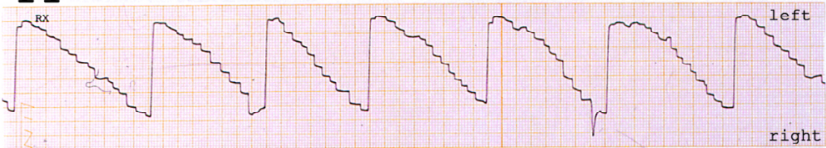

(I) $1, \mathrm{sec}$

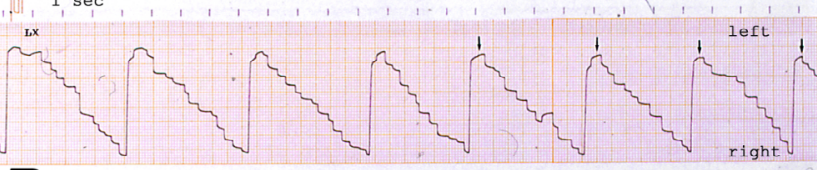

B

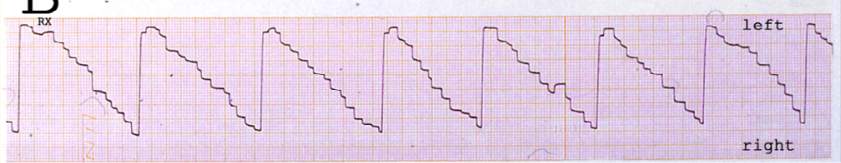

Figure 6: Patient 4. A reading at the VDU, B reading laser -printed texts. Slowly increasing convergent position of LE, $\mathrm{A}>\mathrm{B}$.
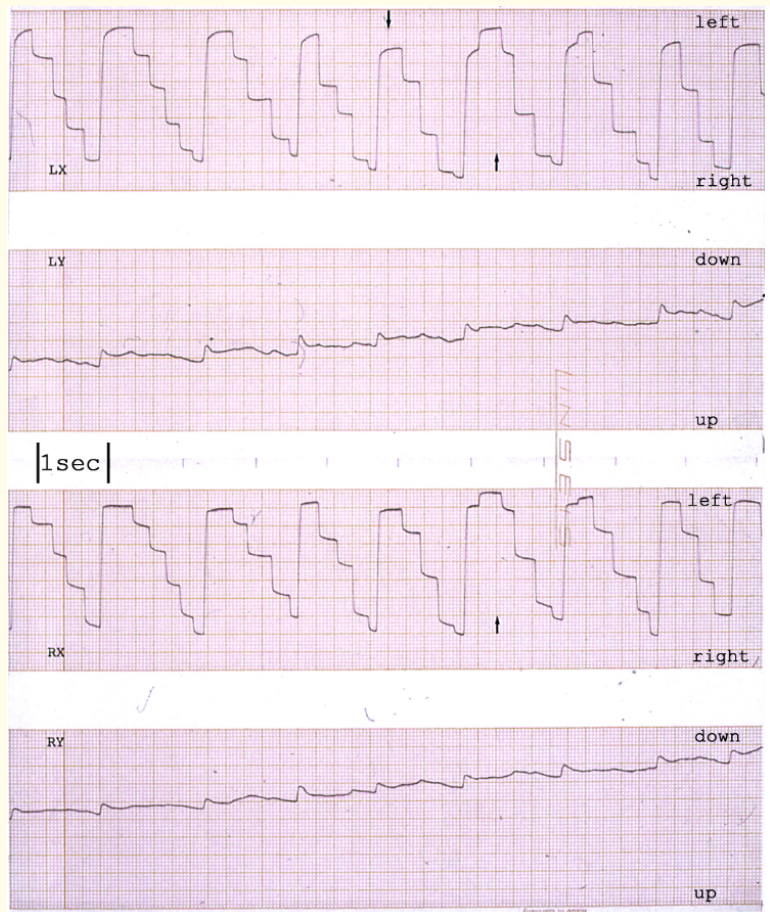

Figure 7: Patient 5, binocular reading of laser-printed text. 
Figure 8 the difference in reading velocity was evident. Horizontal reading traces of the RE while reading laser-printed Text (A) and text on the screen (B). In the same period of time, she read 13 lines with only 2 intermediate fixations each when reading laserprinted text (A), but achieved only 8.8 lines with 3-4 fixations each when reading on the screen (B), which signified a retardation of $32 \%$ in this part of the test.

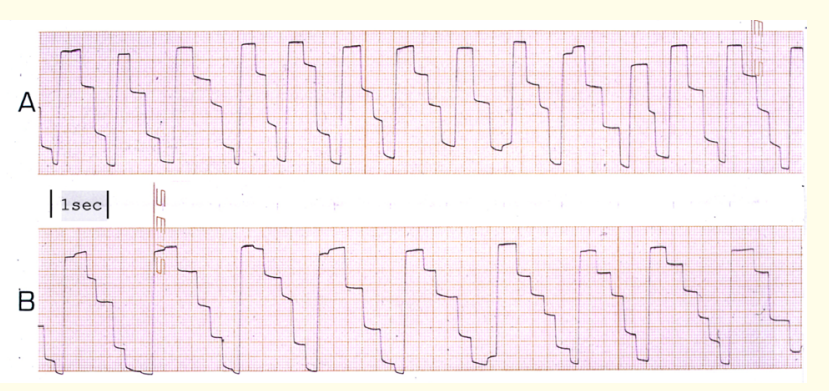

Figure 8: Patient 5, comparison of reading velocity A laserprinted text, B at VDU, monocular traces of RE.

\begin{tabular}{|l|c|c|c|c|c|}
\hline \multicolumn{1}{|c|}{ VDU } & Time & Angle & $\begin{array}{c}\text { Laser- } \\
\text { print }\end{array}$ & Time & Angle \\
\hline Page 1 & $84 \mathrm{sec}$. & $+4^{\circ}$ & Page 1 & $71 \mathrm{sec}$. & $+6^{\circ}$ \\
\hline Page 2 & $81 \mathrm{sec}$. & $+8^{\circ}$ & Page 2 & $63 \mathrm{sec}$. & $+4^{\circ}$ \\
\hline Page 3 & $89 \mathrm{sec}$. & $+8^{\circ}$ & Page 3 & 79 sec. & $+4^{\circ}$ \\
\hline Page 4 & $87 \mathrm{sec}$. & $+10^{\circ}$ & Page 4 & $77 \mathrm{sec}$. & $+4^{\circ}$ \\
\hline & $\begin{array}{c}341 \mathrm{sec} . \\
(+17,6 \%)\end{array}$ & & & $\begin{array}{c}290 \\
\text { sec. }\end{array}$ & \\
\hline
\end{tabular}

Table 1: Case 4, squint angle, reading speed.

\section{Results of the test group}

Comparison of reading speed between the 3 test groups

The data of each group are listed separately in the table 2-4. As the majority of patients were of similar age (between 30 and 40 years), we could rule out any impact of age on the results.

The traces revealed notable differences in individual reading velocities in all groups. Comparison of the individual groups led to the following conclusions (Table 5). All groups revealed a highly significant retardation of reading at the VDU, but not for pin-written texts, regardless of their lower print quality; some persons even preferred pin-writing more than laser-prints. The retardation in reading on the screen was $11 \%$ for normal persons $(p=0.008)$, and $23 \%$ for exophoric persons without symptoms ( $p=0.000)$, although the latter were the fastest readers. Exophoric persons with complaints and only $8.8 \%$ retardation at the screen ( $p=0.003$ ) were apparently at an advantage, but indeed they were the slowest readers and needed $33 \%$ more time to finish the test series than normal persons.

Comparison of the binocular findings between the 3 test groups (Table 6)

The average binocular findings showed that the exophoric patients with complaints had the highest angle of latent squint, the smallest fusion range, the most frequent unilateral suppression, and the weakest convergence.

\begin{tabular}{|l|c|c|c|}
\hline \multicolumn{4}{|c|}{ Reading time in seconds } \\
\hline Age & Laser-printer & Pin-writer & VDU \\
\hline 31 & 149 & $143(-4 \%)$ & $151(+2 \%)$ \\
\hline 30 & 143 & $150(+4.9)$ & $171(+21 \%)$ \\
\hline 20 & 152 & $129(-15 \%)$ & $168(+10,5 \%)$ \\
\hline 32 & 158 & 158 & $192(+21.5 \%)$ \\
\hline 33 & 113 & $102(7.9 \%)$ & $139(+25.6 \%)$ \\
\hline 31 & 147 & $143(-2.7 \%)$ & $150(+2 \%)$ \\
\hline 38 & 200 & $171(-14.5 \%)$ & $172(-14 \%)$ \\
\hline 29 & 135 & $148(+9.6 \%)$ & $173(+28 \%)$ \\
\hline 28 & 131 & 132 & $154(+17.6 \%)$ \\
\hline 31 & 239 & $207(-13.4 \%)$ & $283(+18.4 \%)$ \\
\hline 34 & 205 & $210(+2.4)$ & $224(+9,3 \%)$ \\
\hline 27 & 186 & $181(-2.7)$ & $198(+6.5)$ \\
\hline
\end{tabular}

Table 2: No binocular problems $(n=12)$.

\begin{tabular}{|l|c|c|c|}
\hline \multicolumn{4}{|c|}{ Reading time in seconds } \\
\hline Age & Laser-printer & Pin-writer & VDU \\
\hline 17 & 156 & $169(+18 \%)$ & $191(+22 \%)$ \\
\hline 47 & 118 & $153(+30 \%)$ & $166(+42 \%)$ \\
\hline 35 & 158 & $161(+1.9 \%)$ & $182(+15 \%)$ \\
\hline 31 & 69 & $74(+7.2 \%)$ & $86(+25 \%)$ \\
\hline 33 & 96 & $85(-11.4 \%)$ & $126(+31 \%)$ \\
\hline 30 & 208 & $190(-8.7 \%)$ & $244(+17 \%)$ \\
\hline 22 & 125 & $131(+4.8 \%)$ & $148(+18.4 \%)$ \\
\hline
\end{tabular}

Table 3: Exophoria without complaints $(n=7)$. 


\begin{tabular}{|l|c|c|c|}
\hline \multicolumn{4}{|c|}{ Reading time in seconds } \\
\hline Age & Laser-printer & Pin-writer & VDU \\
\hline 23 & 225 & $221(-1.7 \%)$ & $270(+20 \%)$ \\
\hline 26 & 370 & $385(+4 \%)$ & $173(+24 \%)$ \\
\hline 25 & 290 & $305(+5.1 \%)$ & $341(+17.6 \%)$ \\
\hline 50 & 259 & $262(+1.2 \%)$ & $267(+3.1 \%)$ \\
\hline 30 & 193 & $200(+3.6 \%)$ & $213(+10 \%)$ \\
\hline 52 & 95 & 95 & $100(+5 \%)$ \\
\hline 22 & 156 & $139(-10 \%)$ & 155 \\
\hline 30 & 176 & $197(+12 \%)$ & $194(+10.2 \%)$ \\
\hline 37 & 211 & $192(-9 \%)$ & $208(-1.7 \%)$ \\
\hline 29 & 209 & $195(-6.7 \%)$ & $213(+1,9 \%)$ \\
\hline 38 & 229 & $212(-7.4 \%)$ & $271(+18.3 \%)$ \\
\hline 20 & 250 & $242(-3.2 \%)$ & $255(+2 \%)$ \\
\hline 42 & 139 & $145(+4.3 \%)$ & $173(+24 \%)$ \\
\hline
\end{tabular}

\section{Conclusion}

The retardation of reading speed at the VDU compared to paper-printed texts has been extensively reported in the published literature. In a previous study [3], we noted a difference of about $15 \%$ for normal test persons without considering the binocular state. In the present study, we investigated the reading speed of normal and exophoric persons by registering their eye movements with IROG. Why do some patients experience eye strain whereas others do not?

- The group without complaints showed repeated overcorrections of their latent divergence even into a convergent position (cases 4,5 ) and needed time to regain their "normal" position, but their reading progress or their binocularity were never interrupted. These persons were the best and fastest readers for paper-printed texts. Reading on the screen intensified their binocular instability and thus they lost a lot of time (23\%).

- Test persons with complaints were the slowest readers for paper-printed material. When reading on the screen they showed a speed reduction of just 9\%. Our IROG traces highlighted the difficulties: drifts into divergence, reading stops, unilateral inactivity as a sign of suppression, and fatigue (Case 2,3). These patients had the poorest binocular conditions: the largest squint angle, the lowest fusion range, and weakest convergence power.

- Studying the IROG traces of the second group we remember the Hering's law of equal innervation [4] and notice, this law is not applicable to the micro motility of the eyes. Sometimes one eye may drift away, perhaps due to muscle relaxation, while the other dominant eye receives corrective impulses from subcortical structures such as the control system of accommodation, fusion, and convergence. These corrections occur involuntarily, reflexively, and without perception of diplopia; the limbic system appears to be involved in this process and mediates the patient's feeling of discomfort and strain.

\section{Acknowledgements}

We want to thank Reinhard Müller for technical support and Sujata Wagner for copy-editing the manuscript.

\section{Conflict of Interest}

There is not any conflict of interest.

Table 6: Binocular findings on average. 


\section{Bibliography}

1. Stangler-Zuschrott E. and Bouis D. "Ein neues binokulares Okulometer zur simultanen Registrierung feinster Augenbewegungen". Spektrum Augenheilkd 1 (1987): 113-116.

2. Thömke F. Augenbewegungsstörungen. 2.Aufl. Georg Thieme Verlag, Stuttgart (2008).

3. Harrer S and Stangler-Zuschrott E. "Vergleichende Untersuchungen von Augenbewegungen beim Lesen von Bildschirmschrift und von gedruckten Schriftunterlagen". Spektrum Augenheilk 2/6 (1988): 268-271.

4. Noorden GK. "Binocular Vision and Ocular Motility". Fifth Edition Mosby, St. Louis (1996).

\section{Assets from publication with us}

- Prompt Acknowledgement after receiving the article

- Thorough Double blinded peer review

- Rapid Publication

- Issue of Publication Certificate

- High visibility of your Published work

Website: www.actascientific.com/

Submit Article: www.actascientific.com/submission.php Email us: editor@actascientific.com

Contact us: +919182824667 